\title{
Method to Increase the Coupling Force in a Construction Machine
}

\author{
Il'ja Tsipurskij ${ }^{1, *}$ \\ ${ }^{1}$ Moscow state university of civil engineering, Yaroslavskoye shosse, 26, Moscow, Russia, 129337
}

\begin{abstract}
This paper discusses a possible method to increase the coupling tractive force track-wheel locomotion of construction machines. Sufficient tractive coupling force allows organizing translational displacement of the machine under above-medium load modes during operation of overburden chain excavators, tower cranes and gantry cranes in outdoors environments. A mechanism is examined to convert rotary motion into rectilinear motion using the example of a gear and rail, with kinematic calculations quoted. Analysis of the "force couple" system is proposed to identify free traction forces. Factors are established that influence the machine's working movements. Equations to calculate tractive forces in track-wheel locomotion are described. A laboratory complex is presented where students of mechanical engineering gain practical skills in mastering the production process of soil excavation and the influence of the coupling tractive force during the machine's operation. As practical recommendation, the paper describes a device made of a balancing lever, drive cogwheel and tractive chain to implement the required tractive force of the trolley in coupling; this solution's efficiency is demonstrated for experimental works on hard soils with high coefficient of difficulty.
\end{abstract}

Improvements in mechanization of construction go centuries back. It's amazing how designers come up with new solutions that boost productivity and improve performance of construction machines. According to natural laws, sooner or later the quantity of such novelties must transform into a quantity leap, resulting (theoretically) in a fundamentally new machine or in a dramatically improved mechanization technology for civil construction and assembly. For some 40 years now, complexity of construction equipment has grown many times more compared to its efficiency. And yet, one of the ways to innovations lies through mechanical improvements.

The list of issues related to mechanical improvements in the drive of the track-wheel locomotion mechanism of construction machines includes a scant (by its contribution) solution for one option of boosting the tractive force for coupling of construction machines that run on rail tracks.

The purpose of construction machine undercarriage is to transfer loads to the base and to move the machine proper. The undercarriage includes the drive that interacts with the support base, a suspension and a support frame or axes; self-propelled machines also have a travel mechanism. One of the drive types is the track-wheel on machines used in a limited

\footnotetext{
${ }^{*}$ Corresponding author: cil@,bk.ru
} 
zone, such as tower cranes, bridge and gantry cranes. Wheel track locomotion is also used with excavators for a number of production manipulations such as digging pits along railroad tracks or leveling the track slope. Some types of open-mine continuous-operation cross-digging excavators are also track-mounted when used to strip-mine coal and clay or to level stony slopes around water bodies. The rail track ensures high-precision movements of the excavator and regular thickness of stripped soil, because the rail track is a sort of a guideway [1].

The positive motion drive on a construction machine along the route with a wheel-track enables use of designed modes for permissible tractive forces.

Progressive forward movement of any machine (crane, excavator) is possible if the tractive force generated by the carrier trolleys $T_{\max }$ is at least equal to total resistance to movement $\sum \mathrm{W}$ of the machine proper with the load (on a crane) or the digging equipment (on an excavator):

$$
\mathrm{T}_{\max } \geq \sum \mathrm{W}
$$

Force $\mathrm{T}_{\max }$ is constrained by two factors: the torque moment $\mathrm{M}_{\mathrm{K}}$ of the drive for the lead metal wheels on the trolleys, and their coupling $\mathrm{T}_{\mathrm{c}}$ with the supporting rail. The proportion of torque moment $\mathrm{M}_{д}$ of the motor (in a single-motor drive) applied to the lead wheels of the propulsion mechanism can be represented as tangential tractive force $\mathrm{T}$ on the rim of the metal wheel, multiplied by its radius $\mathrm{R}$. If force $\mathrm{F}_{1}$ that equals the tangential tractive force $\mathrm{T}$ is applied to the center of the driving wheel, and force $F_{2}$ equal and opposed to force $T$, is applied to the wheel rim, then forces $\mathrm{F}_{1}$ and $\mathrm{F}_{2}$ become a pair of forces with arm $\mathrm{R}$ and moment $\mathrm{M}_{\mathrm{K}}$. The discipline of "Classical Mechanics" offers this definition: "The moment of a joined pair as a result of reducing force $A$ applied to point $\mathrm{O}$, equals the moment of such force A relative to point O". The force couple has no equivalent force, and at the same time the combined forces of the couple are not in equilibrium. This means that a couple of forces is an example of a set of forces not in equilibrium and without any equivalent force" [2]. The force couple produces a rotating action that can be evaluated by the pair's moment with arm R:

$$
\mathrm{M}\left(\mathrm{F}_{1}, \mathrm{~F}_{2}\right)=\mathrm{F}_{1} \mathrm{R}=\mathrm{F}_{2} \mathrm{R}
$$

The couple's rotary effect is characterized by a vector value known as the couple's moment. The moment of the force couple relative to point $\mathrm{O}$ :

$$
\mathrm{M}_{\mathrm{O}}\left(\mathrm{F}_{1}, \mathrm{~F}_{2}\right)=\mathrm{M}_{\mathrm{O}}\left(\mathrm{F}_{1}\right)+\mathrm{M}_{\mathrm{O}}\left(\mathrm{F}_{2}\right)
$$

is independent of the selected point $\mathrm{O}$ and equal to the moment of one of the pair of forces relative to the other force's application point $\mathrm{A}$ at point $\mathrm{B}$ :

$$
\mathrm{M}\left(\mathrm{F}_{1}, \mathrm{~F}_{2}\right)=\mathrm{M}_{\mathrm{A}}\left(\mathrm{F}_{1}\right)=\mathrm{M}_{\mathrm{B}}\left(\mathrm{F}_{2}\right) \text {. }
$$

This circumstance conveniently explains the origin of "free" tractive force $\mathrm{T}$, applied at the center of the driving wheel (or two wheels), equal by magnitude to force $F_{1}$ and headed in the same direction. This is the force that drives the propelling wheeled trolley to/from its working pass if it is equal to the grip forces of driving and driven wheels on the rail.

The active traction force is created by the motor's moment $\mathrm{M}_{д}$, applied to the driving wheels of the propulsion mechanism of the trolley. It is known as the tractive force by output, and is defined by this dependence:

$$
\mathrm{T}_{\mathrm{n}}=\mathrm{M}_{д} \cdot \eta_{\mathrm{x}} \cdot \eta_{\mathrm{\kappa}} \cdot \mathrm{i}_{\mathrm{x}} / \mathrm{R}, \mathrm{kN}
$$

where: $\eta_{\mathrm{x}}$ - efficiency of the transmission of the propulsion drive;

$\eta_{\mathrm{K}}$ - efficiency of the metal running wheels;

$\mathrm{i}_{\mathrm{x}}$ - gear ratio of the transmission of the propulsion drive;

$\mathrm{R}$ - radius of the rim of the обода trolley's running wheels

The numerator in the formula stands for torque $\mathrm{M}_{\mathrm{K}}$ on the trolley's driving wheels. This torque is none other but the couple of forces numerically equal to traction force $T_{\Pi}$ with arm $R$. One force $T_{п}$ of the couple heads opposite to the moving direction and applies to the circumference of the driving wheel; the other is $T_{\Pi}$ heading towards its axis and along the 
moving direction. This is exactly the force that moves the trolley, but only if the first force $\mathrm{T}_{\text {пा }}$ can be absorbed by the coupling of the driving and driven wheels with the rail - that is, only if coupling force $\mathrm{T}_{\mathrm{c}}$ exists.

Coupling force $T_{c}$ between the support wheels and the rail is realized by the friction of wheels on the rail. This force is expressed as part of the construction machine weight, and to be more precise, as a reaction of the rail to the driving $\left(\mathrm{R}_{1}\right)$ and driven $\left(\mathrm{R}_{2}\right)$ running wheels. For coupling coefficient $f_{1}$ of the metal wheel and the rail, total traction force for coupling is expressed as:

$$
\sum \mathrm{T}_{\mathrm{c}}=f_{1} \cdot\left(\mathrm{R}_{1}+\mathrm{R}_{2}\right), \mathrm{kN}
$$

The equation of a construction machine moving on full-drive track-wheels in the general case [3] envisages that certain resistance forces must be dealt with: resistance inside the running mechanism assemblies running gear $\mathrm{W}_{\text {вн }}$, resistance of inertial forces when starting from rest $\mathrm{W}_{и}$, resistance to ascent $\mathrm{W}_{\text {п }}$, resistance of wheel on rail $\mathrm{W}_{\text {к }}$, resistance to rotation when passing the curve $\mathrm{W}_{\text {кр }}$. During operation, chain-and-bucket cross-digging excavators have to overcome extra resistance on their working tool $\mathrm{W}_{\text {коп }}$, and thus total resistance to working movement will be:

$$
\sum \mathrm{W}=\mathrm{W}_{\text {вн }}+\mathrm{W}_{\text {и }}+\mathrm{W}_{\text {п }}+\mathrm{W}_{\mathrm{\kappa}}+\mathrm{W}_{\text {кр }}+\mathrm{W}_{\text {коп }}, \mathrm{kN}
$$

In the digging operation mode, one needs to factor in different combinations of resistance forces, and working tool loads $\mathrm{W}_{\text {коп }}$ are made up by resistances to:

$\mathrm{W}_{\mathrm{K}}$ - ground digging by the excavator's chained bucket;

$\mathrm{W}_{\mathrm{r}}$ - gravity of the ground carried to the stacking conveyor;

$\mathrm{W}_{\mathrm{p}}$ - gravity of the chained bucket and its supporting frame

These extra resistances on the excavator's working tool tend to vary most because ground can differ greatly over different sections of the pit face. Even though calculations do envisage different operation modes of the excavator, insufficient coupling of the tractive force compromises the machine's performance. The project envisages that the coupling coefficient for track-wheel machines used outdoors should be $f_{1}=0.12 \div 0.15$, this theoretically ensures tractive force for coupling with the excavator's preset weight. The conclusion sounds commonplace: the excavator's weight (known as coupling weight) should be increased, but this is of course unrealistic.

Another circumstance is relevant for the coupling tractive force $T_{c}$ : wet or iced up rail or the running wheel of the excavator working outdoors. The coupling coefficient declines, and so does coupling tractive force.

The condition that fully enables the movement of any self-propelled machine will be:

$$
\mathrm{T}_{\mathrm{c}} \geq \mathrm{T}_{\mathrm{n}} \geq \sum \mathrm{W} \text {. }
$$

This expression demonstrates that peripheral force $T_{п}$, received by driving wheels from the motor, is able to overcome sum total of resistance $\sum \mathrm{W}$, and coupling force $\mathrm{T}_{\mathrm{c}}$ is sufficient to realize force $T_{\Pi}$.

As the excavator is in use, the following typical condition may arise:

$$
\mathrm{T}_{\mathrm{c}} \geq \mathrm{T}_{\mathrm{\Pi}}<\sum \mathrm{W} \text {. }
$$

This disparity demonstrates that efforts on the wheels are insufficient to overcome resistances and coupling forces, the wheels cannot turn, and the motor will stall.

If coupling coefficient $f_{1}$ is lower, accordingly coupling force $\mathrm{T}_{\mathrm{c}}$ will fade resulting in this disparity:

$$
\mathrm{T}_{\mathrm{c}}<\mathrm{T}_{\mathrm{n}}>\sum \mathrm{W} .
$$

The wheels skid, and the excavator remains without motion.

To increase the trolley's tractive force in coupling, sanding gear is used that raises the coupling coefficient to $f_{1}=0.2$, and in theory enables the excavator operation mode without changing its weight. 
An option of increasing tractive force in coupling is of interest, as it is used at the laboratory test bench "Wheel-Type Rotary Trencher", built at the "Mechanization for Construction" Chair at MGSU (Fig. 1).

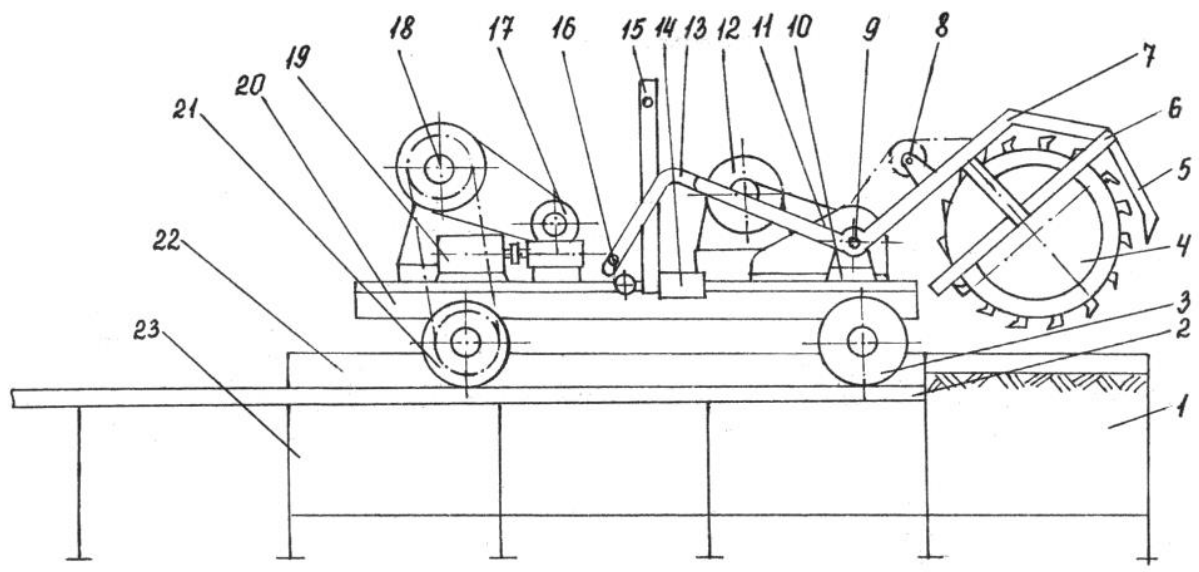

Fig. 1 - Test bench with the wheel-type rotary trenching excavator ( transport position)

The test bench [4] is a physical model of a continuous-action rotary mill, mounted on a trolley (20) that runs on metal rail tracks (2) above a trench (22) filled with ground (1). The trench rests on posts (23). The rotor frame (6) with a shoe plate (5) is secured fast on the frame (7) made as a double-arm lever. The frame lever (13) is connected with a rope to an angle pulley (16) with a drum of worm-gear manual winch (14) used to lift and lower the swing frame and therefore the rotor. As the trench is being excavated while the rotor is fully sun, the lever is rigidly secured on the support post (15). A hinge (9), around which the double-arm lever turns as the rotor moves up and down, stands on the cross beam (10) of the running trolley frame on the test bench, the one nearest to the rotor. The frame rests on the axes of the driven (3) and driving (21) metal wheels that run along the rail track.

The running trolley carries the rotor drive mechanism and the propulsion mechanism. The rotor drive motor (12) acts by means of a parallel-shaft reduction gear (11) to engage a belt transmission and chain transmission and rotate the shaft (8) of the rotor drive sprocket, from which the torque moment is transferred directly to the rotor. The propulsion drive motor (19) acts by means of a worm reduction gear (17) and belt transmission to rotate the countershaft (18) of the propulsion drive sprocket, from which the moment is transferred directly to the two (left and right side of the trolley) driving wheels (21). Adhesion of the wheels and the rail ensures the coupling tractive effort of the trencher.

The operation equipment - the Rotor (4) has two disks: one fixed and one rotating. A sprocket ring is riveted to the inner side of the rotary disk; the ring is engaged with the drive gear that is overhung on the shaft of the driven sprocket of the rotor drive. Over the perimeter of the rotating disk, two removable half-sectors are secured with countersunk screws, to which cog-holding pockets for are welded in staggered rows.

Equipment installed on the running trolley allows no-load operation, rotor in/out movements, and continuous trenching, thus enabling complete operating simulation of a rotary trenching mill.

During trenching at the test bench, the excavator has to overcome the same sum total of reactive resistance $\sum \mathrm{W}$, with breakdown as listed above. Such resistances are overcome with traction forces of power $\mathrm{T}$ and coupling $\mathrm{T}_{\mathrm{c}}$. (Fig. 2) 


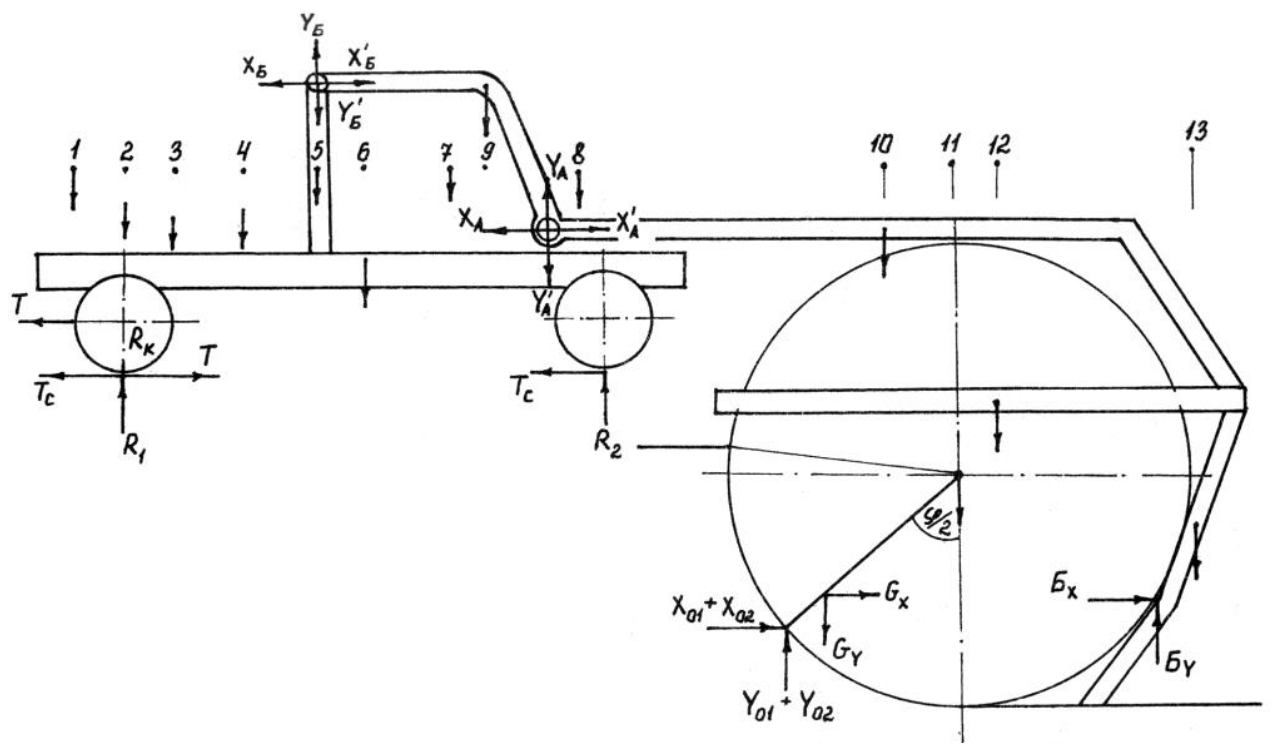

Fig. 2 - Diagram of forces applied to the test bench during excavation

Active forces $T$, and $T_{c}$ and reactive forces $\sum W$ have their respective methodology to find their numeric values when the laboratory test bench trencher is used with different ground handling categories. In particular, resistance to movement by excavation forces $\mathrm{W}_{\text {коп }}$ is created by existing two components (normal $\mathrm{P}_{01}$, and tangential $\mathrm{P}_{02}$ ), that create resistance of ground to excavation, distributed over all cogs currently on the pit face.

Experimental estimated values from the test bench demonstrate that normal operation with stripping thickness up to $10 \mathrm{~cm}$ is only possible with grounds of up to category 3 by excavation difficulty. Work in heavier modes is limited by the coupling force between the rail and the wheel in motion.

To increase the tractive force of the running trolley in coupling, the bench uses a mechanism that converts rotary motion to straight-line motion, such as the cogwheel-rail pair [5]. As the rail, the bench uses the sagging part of the chain supported by the rollers of the balancing lever. The chain's one end is secured on the metal structure opposite to the working pass of the trencher while excavating; the other one, partly going round the sprocket on a $120^{\circ} \mathrm{arch}$, lies in the guides along the trench in progress. The sprocket sits rigidly on the driving wheel shaft and a balancing lever is mounted centrally with two rollers (Fig. 3).

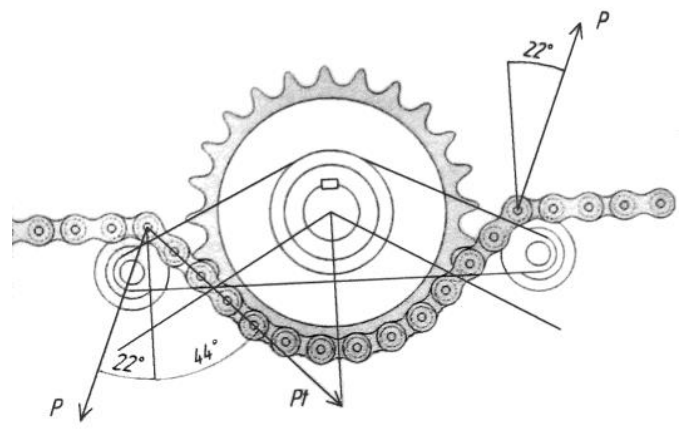

Fig. 3 - Balancing lever and drive cogwheel engaged with chain 
The diameter of the reference circle of the sprocket is equal to that of the outer diameter of the driving metal wheels (21) of radius $R_{\mathrm{K}}$. The arch of sprocket engagement on the chain is adjusted with a dedicated balancing lever that has deflecting rollers. Locations of the rollers are assumed structurally such that the chain can engage the sprocket at an angle that ensures normal distribution of loads over the chain joints in contact. Chain tension $\mathrm{P}_{\mathrm{t}}$ adequately makes up for the tractive force in coupling in the event of disparity (10).

The progressive movement speed $(\mathrm{mm} / \mathrm{min})$ of the sprocket is found using this formula:

where:

$$
\mathrm{V}=\mathrm{n} \cdot \pi \cdot \mathrm{m} \cdot \mathrm{z} \text {, }
$$

$\mathrm{n}$ - rotation frequency of sprocket (driving wheel, $\min ^{-1}$ );

$\mathrm{m}$ - engagement modulus, $\mathrm{mm}$;

$\mathrm{z}$ - number of sprocket cogs

The above method of increasing the tractive force in coupling by improving the mechanics of the rail track drive helps to realize heavier modes of excavator operation, because tractive force by power is usually sufficient to meet the requirement of necessary and sufficient movement of the excavator during ground excavation:

$$
\mathrm{T}_{\mathrm{n}} \geq \mathrm{T}_{\mathrm{c}} \geq \sum \mathrm{W} \text {. }
$$

Considering the problems with the national economy at present, it is best to invest in mechanical retrofitting or upgrade of the existing construction machines, ensuring rapid payback, rather than investing heavily to create fundamentally new samples and solutions, complete with expensive electronics that is also unreasonably difficult to service.

\section{References}

1. N.G.Dombrovsky, M.I.Galperin, Construction. Machines, Ch.P., M. "Higher School", M.. - 224 (1989)

2. Internet, "Pair of forces", Section "Statics", "Theoretical mechanics", ISopromat.ru

3. I.L Tsipursky Settings digging and recruitment earthmoving machines: textbook/Publisher ASV 223 (2016)

4. I.L. Tsipursky Determination of the parameters of soil excavating, Manual, / MGSU, 107 (1998)

5. Internet Toothed rack and pinion transmission www.promtechnoservice.ru

6. I.L. Tsipursky Excavator with working equipment dragline and grapple: Proc. Pos. / M . MGSU, 56 (2011)

7. I.L. Tsipursky Increase traction of the rail track model excavator // Mechanization of construction. 11 (857), 7-8 (2015)

8. Road-building machines and complexes: Textbook for high schools / V.I. Balovnev et al .; Under the Society. Ed. IN AND. Balovneva. - 2 nd ed., Supplement. And pererab. - Moscow-Omsk: Publishing House of SibADI, (2001)

9. I.L. Tsipursky The influence of teeth on the remote ability of the milling rotor // Interstroymech, International Conference M.- (2016)

10. A.A. Bogomolov Machines for earthmoving: Textbook for high schools / Belgorod: Izd. BSTU. VG Shukhov. - 314

11. Y.A., Verigin, N.S. Sevryugina. Synergetic foundations of processes and technologies - a new course in master's preparation in the direction of "Construction" // "Guarantees of the quality of vocational education". Abstracts of the reports of the ISPM, (2012) 
12. S.N., Glagolev T.A., Duyun, N.S., Sevryugina Problems of engineering education in the field of engineering and technology: a training manual. - Belgorod: Belgorod State Technological University. V.G. Shukhova, (2013)

13. A.N. Drozdov Building machines and equipment: a textbook for the stud. Institutions of

14. E.M. Kudryavcev Construction machines and equipment: Textbook. -M.Discovery of the ASV, 2012.- 328 p higher education / M .: Izd. Center "Academy", (2012)

15. V.I. Balovnev Machines for excavation: construction, calculation, consumer properties: Book 1. Excavators and earth-moving machines: Ucheb. Allowance. Belgorod: BSTU Publishing House, (2011) 